\title{
Metabolismo de nitrogênio em novilhas alimentadas com dietas contendo cana-de-açúcar tratada com óxido de cálcio ${ }^{1}$
}

\section{Gleidson Giordano Pinto de Carvalho², Rasmo Garcia ${ }^{3,8}$, Aureliano José Vieira Pires ${ }^{4,8}$, Edenio Detmann ${ }^{3,7}$, Robério Rodrigues Silva ${ }^{5}$, Mara Lúcia Albuquerque Pereira ${ }^{5}$, Alana Batista dos Santos ${ }^{6}$, Taiala Cristina de Jesus Pereira ${ }^{7}$}

\author{
1 Projeto financiado pelo CNPq. \\ 2 Departamento de Produção Animal/UFBA, Salvador, BA \\ ${ }^{3}$ Departamento de Zootecnia/UFV, Viçosa, MG. \\ ${ }^{4}$ Departamento de Tecnologia Rural e Animal/UESB, Itapetinga, BA. \\ ${ }^{5}$ Departamento de Estudos Básicos e Instrumentais/UESB, Itapetinga, BA. \\ ${ }^{6}$ Mestranda em Zootecnia/UESB, Itapetinga, BA. \\ 7 Graduanda em Zootecnia/UESB, Itapetinga, BA. \\ 8 Pesquisador do CNPq.
}

RESUMO - Esta pesquisa foi realizada para avaliar o balanço de nitrogênio, as concentrações de ureia na urina e no plasma e a síntese de proteína microbiana em novilhas alimentadas com dietas contendo cana-de-açúcar tratada com óxido de cálcio. Utilizaram-se 20 novilhas mestiças Holandês-Zebu com peso corporal médio inicial de $200 \mathrm{~kg}$ distribuídas em delineamento inteiramente ao acaso, com quatro tratamentos e cinco repetições. Os animais foram alojados em baias individuais cobertas, com piso de concreto, providas de cocho individual de concreto para alimentação e bebedouro automático comum a duas baias. O período experimental foi de 21 dias, e a coleta de dados foi realizada nos sete dias finais. As dietas foram formuladas para ser isoproteicas, com $14 \%$ de proteína bruta, e continham $71 \%$ de cana-de-açúcar (com 0; 0,75; 1,5 ou 2,25\% de óxido de cálcio na matéria natural) corrigida com 1\% de mistura ureia e sulfato de amônio (9:1) e 29\% de concentrado. A canade-açúcar foi fornecida aos animais após 24 horas de tratamento com óxido de cálcio. O tratamento da cana-de-açúcar com óxido de cálcio influenciou o balanço de nitrogênio, pois ocasionou redução tanto no consumo como na quantidade de nitrogênio digerido e retido. O nitrogênio retido (em \% do $\mathrm{N}$ ingerido e do $\mathrm{N}$ digerido) também reduziu linearmente conforme aumentaram os níveis de óxido de cálcio na cana-de-açucar. O uso de óxido de cálcio em níveis de até 2,25\% no tratamento da cana-de-açúcar não afeta as concentrações de ureia na urina e no plasma nem a excreção de ureia na urina e a síntese de proteína microbiana em novilhas.

Palavras-chave: cal, plasma, purinas microbianas, retenção de nitrogênio

\section{Nitrogen metabolism in heifers fed with diets containing sugar cane treated with calcium oxide}

\begin{abstract}
This study was carried out to evaluate the nitrogen balance, the urea concentrations in urine and plasma and the microbial protein synthesis in heifers fed diets containing sugar cane treated with calcium oxide. Twenty Holsteinzebu crossbred heifers, with average initial body weight of $200 \mathrm{~kg}$ were used, distributed in a completely randomized design, with four treatments and five repetitions. The animals were housed in covered individual stalls, with concrete floor, provided with individual concrete trough for feeding and automatic drinkers common for every two stalls. The experimental period was of 21 days, and data collection was performed on the last seven days. The diets were formulated to be isoprotein, with14\% crude protein and they contained $71 \%$ sugar cane (with 0 ; $0.75 ; 1.5$ or $2.25 \% \mathrm{CaO}$, in natural matter) corrected with $1 \%$ of urea and ammonium sulfate (9:1) and 29\% of concentrate. Sugar cane was offered to the animals after 24 hours of treatment with chromium oxide. Treatment of sugar cane with calcium oxide affected nitrogen balance by reducing intake and quantity of retained and digested nitrogen. The retained nitrogen (in \% of ingested $\mathrm{N}$ and digested $\mathrm{N}$ ) was also linerarly reduced according to increases in levels of calcium oxide in the sugar cane. Use of calcium oxide at levels up to $2.25 \%$ in sugar cane treatment does not affect concentrations of urea in the urine and in the plasma neither the urine urea excretion and the microbial protein synthesis in dairy heifers.
\end{abstract}

Key Words: microbial purines, nitrogen retention, plasma, whitewash

Recebido em 11/5/2009 e aprovado em 9/3/2010.

Correspondências devem ser enviadas para: gleidsongiordano@ufba.br. 


\section{Introdução}

Os problemas decorrentes da sazonalidade de produção de forragem no Brasil podem provocar grandes prejuízos na criação de animais, que podem ser reduzidos com o uso de volumosos como a cana-de-açúcar, especialmente no período seco. O uso da cana-de-açúcar na dieta de bovinos tem sido justificado pelo fato de que essa forrageira é de fácil cultivo e elevada produção de energia, com baixo custo de matéria seca produzida por unidade de área cultivada. Além disso, seu período de maior disponibilidade coincide com o de escassez de forragem e a manutenção do valor nutritivo por longo tempo após a maturação (Fernandes et al., 2001; Magalhães et al., 2004).

O uso de aditivos químicos como forma de melhorar o valor nutritivo da cana-de-açúcar tem sido avaliado por diversos autores (Oliveira et al., 2007; Balieiro Neto et al., 2007; Ribeiro et al., 2010). A utilização do óxido de cálcio e do hidróxido de sódio nesses estudos tem como finalidade provocar alterações na fração fibrosa, por meio da solubilização de componentes da parede celular, como a hemicelulose, e o rompimento dessas estruturas, para promover melhorias significativas na digestibilidade da cana-de-açúcar, uma vez que a baixa digestibilidade dos componentes da parede celular desse volumoso é apontada como um dos principais entraves à sua plena utilização na alimentação de ruminantes.

A utilização de ureia em dietas para ruminantes tem sido uma opção viável de fornecimento de nitrogênio para suprir a demanda ruminal, a síntese microbiana. No caso específico da cana-de-açúcar, que apresenta baixos teores de proteína, a ureia tem sido excelente alternativa para corrigir a deficiência proteica. O fornecimento de fontes extras de nitrogênio não-proteico, no entanto, pode provocar perdas nitrogenadas, pois, de acordo com Valadares et al. (1997), concentrações de $\mathrm{N}$ no plasma e na urina estão relacionadas, de modo que valores entre 14,0 e 16,0 mg/dL de $\mathrm{N}$-ureico plasmático representariam limites a partir dos quais iniciaram as perdas de proteína dietética.

Apesar de melhorar o valor nutritivo da cana-deaçúcar, o óxido de cálcio, por ser um aditivo alcalino, pode provocar alterações no ambiente ruminal e modificar os padrões de fermentação, prejudicando a eficiência microbiana na síntese e no metabolismo de nitrogênio. Desse modo, o experimento foi realizado para avaliar o balanço de nitrogênio, as concentrações de ureia na urina e no plasma e a síntese de proteína microbiana em novilhas alimentadas com dietas contendo cana-deaçúcar tratada com óxido de cálcio.

\section{Material e Métodos}

O experimento foi conduzido no Laboratório de Animais e no Laboratório de Forragicultura e Pastagem da Universidade Estadual do Sudoeste da Bahia, Itapetinga, BA, utilizando-se 20 novilhas mestiças Holandês-Zebu ( $3 / 4$ Gir $\times$ Holandês) com peso corporal médio inicial de $200 \mathrm{~kg}$ distribuídas em delineamento experimental inteiramente casualizado com quatro tratamentos e cinco repetições.

Os animais foram alojados em baias individuais cobertas, com piso de concreto, providas de cocho individual de concreto para alimentação e bebedouro automático comum a duas baias e alimentados com de cana-de-açúcar hidrolisada (71\% da dieta) com óxido de cálcio nos níveis 0; 0,$75 ; 1,5$ e $2,25 \%$ da matéria natural e concentrado, $29 \%$ (Tabela 1).

A cana-de-açúcar sem óxido de cálcio foi desintegrada e fornecida no momento do oferecimento das dietas, todos os dias, pela manhã e pela tarde.

A cana-de-açúcar em todos os tratamentos, no momento do fornecimento aos animais foi corrigida com $1 \%$ da mistura ureia/sulfato de amônio (9:1) na base da matéria natural. Nesse procedimento, a ureia foi previamente pesada de acordo com a quantidade de cana estimada em cada tratamento, diluída em água (mantendo sempre a relação de 1 kg de ureia/litro de água) e distribuída à cana-de-açúcar com o auxílio de um regador. As dietas (Tabela 2) foram calculadas para serem isoproteicas (14\% de PB) e conterem nutrientes suficientes para ganho de peso de $0,6 \mathrm{~kg} / \mathrm{dia}$ (NRC, 2001).

As doses de óxido de cálcio aplicadas a cana-de-açúcar foram calculadas com base na matéria natural, sem diluição em água. A cana-de-açúcar foi processada em desintegrador estacionário, pesada e espalhada em piso de alvenaria e tratada com o óxido de cálcio. Em seguida, foi armazenada e fornecida aos animais após 24 horas.

O experimento teve duração de 21 dias, sendo 14 dias destinados à adaptação dos animais e sete dias de coleta.

Tabela 1 - Composição do concentrado e da dieta (\% na MS)

\begin{tabular}{lcc}
\hline Ingrediente & Concentrado & Dieta \\
\hline Cana-de-açúcar & & 71,0 \\
Fubá de milho & - & 15,9 \\
Farelo de soja & 54,8 & 11,4 \\
Calcário calcítico & 39,4 & 0,59 \\
Fosfato bicálcico & 2,0 & 0,46 \\
Mistura mineral $^{2}$ & 1,5 & 0,65 \\
\hline
\end{tabular}

${ }^{1}$ Cana-de-açúcar com óxido de cálcio ( $0 ; 0,75 ; 1,5$ ou 2,25\% na MN) e adicionada de $1 \%$ da mistura ureia + sulfato de amônio (9:1) (\%MN).

2 Quantidade/kg do produto: cálcio - $175 \mathrm{~g}$; fósforo - $60 \mathrm{~g}$; sódio - $107 \mathrm{~g}$; magnésio - 5 g; enxofre - 12 g; cobalto - $70 \mathrm{mg}$; cobre - $1.200 \mathrm{mg}$; iodo - $70 \mathrm{mg}$; manganês - $1.000 \mathrm{mg}$; níquel - $30 \mathrm{mg}$; selênio - $18 \mathrm{mg}$; zinco - $4.000 \mathrm{mg}$; ferro $14.000 \mathrm{mg}$. 
Tabela 2 - Composição nutricional das dietas experimentais

\begin{tabular}{|c|c|c|c|c|}
\hline \multirow[t]{2}{*}{ Item } & \multicolumn{4}{|c|}{ Óxido de cálcio na cana-de-açúcar (\% da matéria natural) } \\
\hline & 0 & 0,75 & 1,5 & 2,25 \\
\hline Matéria seca & 45,3 & 47,9 & 48,5 & 49,0 \\
\hline Proteína bruta (\% MS) & 14,6 & 14,7 & 14,4 & 14,8 \\
\hline PIDN (\% PB) & 17,8 & 22,1 & 21,3 & 22,9 \\
\hline PIDA (\% PB) & 8,6 & 12,2 & 11,9 & 7,6 \\
\hline Carboidratos totais (\% MS) & 74,6 & 74,1 & 73,6 & 71,9 \\
\hline Fibra em detergente neutro (\% MS) & 54,0 & 54,0 & 51,5 & 50,0 \\
\hline FDNcp (\% MS) & 48,9 & 48,6 & 46,3 & 43,1 \\
\hline FDNi (\% MS) & 21,7 & 22,1 & 20,4 & 17,0 \\
\hline FDNpD & 32,3 & 31,9 & 31,1 & 33,0 \\
\hline Carboidratos não-fibrosos (\% MS) & 25,7 & 25,5 & 27,3 & 28,8 \\
\hline Lignina (\% MS) & 5,2 & 5,7 & 5,0 & 4,3 \\
\hline MSpD (\% MS) & 77,4 & 77,0 & 78,6 & 82,1 \\
\hline Nutrientes digestíveis totais $(\% \mathrm{MS})^{1}$ & 61,4 & 60,7 & 62,5 & 62,9 \\
\hline
\end{tabular}

${ }^{1}$ Estimado segundo NRC (2001).

Os alimentos foram fornecidos à vontade, duas vezes ao dia, às $7 \mathrm{~h} 30$ e às $15 \mathrm{~h} 30$, e ajustados de forma a manter as sobras em torno de 5 a $10 \%$ do fornecido, com água permanentemente à disposição dos animais. Durante todo o experimento, a quantidade de alimentos oferecida foi registrada diariamente e, no período de coleta, $15^{\circ} \underline{0}$ ao $21^{\circ} \stackrel{0}{ }$ dia, amostras dos volumosos, concentrado e das sobras de cada animal foram coletadas diariamente, acondicionadas em sacos plásticos e armazenadas em freezer.

As amostras dos alimentos coletados foram pré-secas em estufa com ventilação forçada a $60^{\circ} \mathrm{C}$ e processadas em moinho de faca (peneira com crivos de $1 \mathrm{~mm}$ ) para análises químicas posteriores. As análises de matéria seca (MS), matéria orgânica (MO), proteína bruta (PB), extrato etéreo (EE), fibra em detergente neutro (FDN), fibra em detergente ácido (FDA), proteína insolúvel em detergente neutro (PIDN), proteína insolúvel em detergente ácido (PIDA) celulose, hemicelulose e lignina $\left(\mathrm{H}_{2} \mathrm{SO}_{4} 72 \% \mathrm{p} / \mathrm{p}\right)$ foram realizadas segundo procedimentos descritos por Silva \& Queiroz (2002) e as de fibra em detergente neutro corrigido para cinzas e proteína, segundo recomendações de Licitra et al. (1996) e Mertens (2002).

As estimativas dos teores de fibra em detergente neutro potencialmente digestível (FDNpD) e de matéria seca potencialmente digestível (MSpD) dos alimentos foram obtidas de acordo com Paulino et al. (2006).

Os carboidratos totais (CT) foram estimados segundo Sniffen et al.(1992), como: CT = 100-(\%PB+\%EE+\%cinzas). Os teores de carboidratos não-fibrosos corrigidos para cinzas e proteína (CNFcp) foram calculados como proposto por Hall (2003), em que: $\mathrm{CNFcp}=(100-\% \mathrm{FDNcp}-\% \mathrm{~PB}-$ $\%$ EE -\%cinzas).

Os nutrientes digestíveis totais (NDT) foram calculados segundo Weiss (1999), porém utilizando a FDN e CNF corrigindo para cinza e proteína, pela seguinte equação:

NDT $(\%)=$ PBD + FDNcpD + CNFcpD + 2,25EED . em que: $\mathrm{PBD}=\mathrm{PB}$ digestível; FDNcpD = FDNcp digestível; $\mathrm{CNF} c \mathrm{D}$ = CNFcp digestíveis; e EED = EE digestível .

Os teores de nutrientes digestíveis totais estimados (NDTest) dos alimentos e das dietas totais foram calculados conforme equações descritas pelo NRC (2001).

A coleta de fezes dos animais foi realizada em durante dois dias alternados, em horários diferentes (às 8 h e às $16 \mathrm{~h}$ ) entre o $20^{\circ}$ e $21^{\circ}$ dia do experimento, conforme descrito por Ítavo et al. (2002). As amostras de fezes foram pré-secas, moídas em moinho de faca com peneira de malha de $1,0 \mathrm{~mm}$, compostas por animal e posteriormente armazenadas para as análises. Para a estimativa da excreção fecal, foi utilizada a fibra em detergente neutro indigestível (FDNi) como indicador interno (Detmann et al., 2001; Detmann et al., 2007). Amostras dos alimentos fornecidos (cana, concentrado) e das sobras foram incubadas por 240 horas (Casali et al., 2008) em duplicata (20 mg MS/ $/ \mathrm{cm}^{2}$ ) em sacos de tecidonão-tecido (TNT - $100 \mathrm{~g} / \mathrm{m}^{2}$, conforme Casali et al., 2009) no rúmen de um novilho mestiço Holandês-Zebu recebendo dieta mista. Após esse período, o material remanescente da incubação foi submetido à extração com detergente neutro (Mertens, 2002) para quantificação dos teores de FDNi. Os 
valores de excreção fecal foram obtidos pela relação entre consumo e concentração fecal de FDNi.

No $21^{\underline{o}}$ dia foram realizadas coletas de urina, spot, em micção espontânea dos animais, aproximadamente 4 horas após o fornecimento da alimentação matinal, conforme descrito por Barbosa (2005). As amostras foram filtradas em gaze e uma alíquota de $10 \mathrm{~mL}$ foi separada e diluída com 40 mL de ácido sulfúrico (0,036 N) (Valadares et al., 1999) e destinada à quantificação das concentrações urinárias de ureia, nitrogênio, creatinina, alantoína e ácido úrico.

A coleta de sangue foi realizada na veia jugular, no $21^{\circ}$ dia, aproximadamente 4 horas após o fornecimento da alimentação da manhã, utilizando-se tubos (Vacutainer ${ }^{T M}$ ) de $5 \mathrm{~mL}$ com EDTA. Em seguida, as amostras de sangue foram transferidas para o laboratório, centrifugadas a 3.500 rpm por 10 minutos e o plasma acondicionado em microtubos de $5 \mathrm{~mL}$, foi mantido congelado $\left(-20^{\circ} \mathrm{C}\right)$ até a realização das análises.

As concentrações de creatinina e ácido úrico na urina e de ureia na urina e no plasma foram estimadas utilizando-se kits comerciais (Bioclin). A conversão dos valores de ureia em nitrogênio ureico foi realizada pela multiplicação dos valores obtidos pelo fator 0,4667 . Os teores urinários de alantoína e ácido úrico foram estimados por métodos colorimétricos, conforme especificações de Chen \& Gomes (1992), e o teor de nitrogênio total estimado pelo método de Kjeldhal (Silva \& Queiroz, 2002).

Obalanço denitrogênio(N-retido, g/dia) foi calculado como: $\mathrm{N}$-retido $=\mathrm{N}$ ingerido $(\mathrm{g})-\mathrm{N}$ nas fezes $(\mathrm{g})-\mathrm{N}$ na urina $(\mathrm{g})$.

A excreção de creatinina (mg/kg PV) utilizada para estimar o volume urinário por intermédio das amostras spots foi obtida para cada animal, segundo a equação descrita por Chizzotti (2004):

$\mathrm{EC}=32,27-0,01093 \times \mathrm{PV}$

em que: EC = excreção diária de creatinina (mg/kg PV); e $\mathrm{PV}=$ peso vivo $(\mathrm{kg})$.

O volume urinário, contudo, foi estimado a partir da relação entre a excreção de creatinina (mg/kg PV/dia) obtida na equação anterior e a concentração média nas amostras de urina (mg/dL), multiplicando-se pelo respectivo peso vivo do animal.

A excreção de purinas totais (PT) foi estimada pela soma das quantidades de alantoína e ácido úrico excretadas na urina e a quantidade de purinas microbianas absorvidas (mmol/dia), pela excreção de purinas totais (mmol/dia), por meio da equação proposta por Verbic et al. (1990):

$$
\mathrm{PA}=\frac{\mathrm{PT}-0,385 \times \mathrm{PV}^{0,75}}{0,85}
$$

em que: $\mathrm{PA}=$ purinas absorvidas $(\mathrm{mmol} / \mathrm{dia}) ; \mathrm{e} \mathrm{PT}=$ purinas totais (mmol/dia).; 0,85 = recuperação de purinas absorvidas como derivados de purina na urina; e 0,385 = excreção endógena de derivados de purina na urina (mmol) por unidade de tamanho metabólico. O fluxo intestinal de nitrogênio microbiano (g NM/dia) foi estimado a partir da quantidade de purinas absorvidas (mmol/dia), segundo a equação de Chen \& Gomes (1992):

$$
\mathrm{NM}(\mathrm{g} / \mathrm{dia})=\frac{70 \times \mathrm{PA}}{0,83 \times 0,116 \times 1000}
$$

Assumindo-se o valor de 70 para o conteúdo de nitrogênio nas purinas ( $\mathrm{mg} / \mathrm{mmol}) ; 0,83$ para a digestibilidade intestinal das purinas microbianas e 0,116 para a relação $\mathrm{N}_{\text {PURINA }}: \mathrm{N}_{\text {TOTAL }}$ nas bactérias.

Nas análises estatísticas dos resultados, procedeu-se à decomposição da soma de quadrados relacionada às doses de óxido de cálcio na cana-de-açúcar, por meio de contrastes ortogonais (Tabela 3).

Ao primeiro contraste (A) atribuiu-se a comparação entre as médias da dieta controle (cana in natura) e daquela contendo cana-de-açúcar com óxido de cálcio. Os contrastes representados pelas letras B e C permitiram a avaliação de efeitos de ordem linear e quadrática das doses de óxido de cálcio na cana-de-açúcar, respectivamente. Os procedimentos estatísticos foram realizados pelo programa SAS (Statistical Analisys System), adotando-se 0,05 como nível crítico de probabilidade.

Tabela 3 - Distribuição dos coeficientes em contrastes ortogonais empregados na decomposição da soma de quadrados para tratamentos

\begin{tabular}{ccccc}
\hline & \multicolumn{4}{c}{ Coeficiente } \\
\cline { 2 - 5 } Contraste & Cana in natura & 0,75 & 1,5 & 2,25 \\
\hline A & +3 & -1 & -1 & -1 \\
B & 0 & -1 & 0 & +1 \\
C & 0 & -1 & +2 & -1 \\
\hline
\end{tabular}

A - Cana in natura vs. cana com óxido de cálcio; B - linear; C - efeito quadrático.

\section{Resultados e Discussão}

Os menores valores de consumo de nitrogênio, nitrogênio digerido (em g/dia e em \% do $\mathrm{N}$ ingerido) e nitrogênio retido (g/dia, \% do ingerido e em \% do digerido) foram observados nos animais que receberam a cana-deaçúcar tratada com óxido de cálcio (Tabela 4). As doses de óxido de cálcio na cana-de-açúcar promoveram decréscimo linear no teor de $\mathrm{N}$ digerido, tanto em g/dia $(\mathrm{P}<0,05)$ como em \% do $\mathrm{N}$ ingerido $(\mathrm{P}<0,01)$, e no balanço de nitrogênio ( $\mathrm{P}<0,01)$ (Tabela 4). Contudo, a excreção de nitrogênio via fezes e urina não foi afetada $(\mathrm{P}>0,05)$ pelas doses de óxido de cálcio na cana-de-açúcar. 
Tabela 4 - Balanço de compostos nitrogenados, concentrações de N-ureico na urina e no plasma e excreções de uréia e Nureico na urina em novilhas alimentadas com dietas contendo cana-de-açúcar tratada com óxido de cálcio

\begin{tabular}{|c|c|c|c|c|c|c|c|c|}
\hline \multirow[t]{3}{*}{ Item } & \multirow{3}{*}{$\begin{array}{l}\text { Cana in } \\
\text { natura }\end{array}$} & \multirow{2}{*}{\multicolumn{3}{|c|}{$\begin{array}{l}\text { Óxido de cálcio na } \\
\text { cana-de-açúcar (\% MN) }\end{array}$}} & \multirow{3}{*}{$\begin{array}{l}\text { Coeficiente de } \\
\text { variação (\%) }\end{array}$} & \multicolumn{3}{|c|}{ Efeito $^{1}$} \\
\hline & & & & & & \multirow{2}{*}{$\begin{array}{l}\text { Controle vs. } \\
\text { óxido de cálcio }\end{array}$} & \multirow[t]{2}{*}{ Linear } & \multirow{2}{*}{ Quadráticc } \\
\hline & & 0,75 & 1,5 & 2,25 & & & & \\
\hline N-ingerido (g/dia) & 152,5 & 131,3 & 111,1 & 97,7 & 27,8 & $*$ & ns & ns \\
\hline N-fezes (g/dia) & 38,1 & 31,5 & 34,0 & 34,6 & 30,7 & ns & ns & ns \\
\hline N-digerido (g/dia $)^{2}$ & 114,5 & 99,8 & 77,1 & 63,3 & 28,4 & $*$ & $*$ & ns \\
\hline $\mathrm{N}$-digerido (\% do $\mathrm{N}$-ingerido $)^{3}$ & 75,9 & 75,5 & 68,8 & 64,2 & 4,9 & $* *$ & $* *$ & ns \\
\hline N-urina (g/dia) & 53,2 & 54,4 & 55,8 & 47,1 & 27,2 & ns & ns & ns \\
\hline N-retido (g/dia) ${ }^{4}$ & 61,2 & 45,4 & 21,2 & 16,1 & 42,8 & $* *$ & $* *$ & ns \\
\hline $\mathrm{N}$-retido (\% do ingerido $)^{5}$ & 41,2 & 33,2 & 17,9 & 15,4 & 29,8 & $* *$ & $* *$ & ns \\
\hline N-retido (\% do digerido) ${ }^{6}$ & 54,0 & 43,9 & 25,7 & 23,8 & 26,7 & $* *$ & $* *$ & ns \\
\hline \multicolumn{9}{|l|}{ Concentrações (mg/dL) } \\
\hline N-ureico na urina & 513,0 & 582,4 & 574,6 & 591,9 & 39,7 & ns & ns & ns \\
\hline N-ureico no plasma & 16,5 & 15,2 & 14,7 & 15,9 & 13,8 & ns & ns & ns \\
\hline \multicolumn{9}{|l|}{ Excreções (g/dia) } \\
\hline Ureia na urina & 100,6 & 99,3 & 110,1 & 91,9 & 29,9 & ns & ns & ns \\
\hline $\mathrm{N}$-ureico na urina & 44,9 & 44,3 & 49,2 & 41,0 & 29,9 & ns & ns & ns \\
\hline \multicolumn{9}{|l|}{ Excreções (mg/kg PV) } \\
\hline Ureia na urina & 462,8 & 451,8 & 512,8 & 417,7 & 24,0 & ns & ns & ns \\
\hline N-ureico na urina & 206,7 & 201,8 & 229,0 & 186,5 & 24,0 & ns & ns & ns \\
\hline
\end{tabular}

${ }^{1}$ (ns), $\left({ }^{*}\right)$ e $\left(^{* *}\right)$ : não-significativo (P>0,05) e significativo a 0,05 e 0,01 de probabilidade, respectivamente. ${ }^{2} \hat{Y}=16,541-24,3411 X\left(\mathrm{r}^{2}=0,9807\right) .{ }^{3} \hat{Y}=80,7663-7,49334 \mathrm{X}$ $\left(\mathrm{r}^{2}=0,9897\right) \cdot{ }^{4} \hat{Y}=56,8204-19,4919 X\left(r^{2}=0,8762\right) .{ }^{5} \hat{Y}=40,0008-11,9011 X\left(r^{2}=0,8520\right) \cdot{ }^{6} \hat{Y}=51,2247-13,3983 X\left(r^{2}=0,8222\right)$.

O tratamento da cana-de-açúcar com óxido de cálcio teve efeito negativo sobre o consumo de nitrogênio (g/dia), o que pode estar relacionado à modificação dos padrões fermentativos por ocasião do uso do óxido de cálcio. Esses resultados estão de acordo com os observados por Moraes et al. (2008), que avaliaram a cana-de-açúcar tratada com $1 \%$ de óxido de cálcio 24 horas antes do fornecimento e, do mesmo modo, observaram menor ingestão de nitrogênio. Tudo indica que a redução na ingestão de nitrogênio e fatores relacionados ao metabolismo ruminal refletiram no teor de nitrogênio digerido e no balanço de nitrogênio, que reduziram com o tratamento da cana-de-açúcar com óxido de cálcio. Considerando o pH de 5,7; 7,7; 9,9 e 11,8 observado na cana-de-açúcar tratada com 0; 0,75; 1,5 e 2,25\%, é possível que o $\mathrm{pH}$ ruminal nos animais alimentados com a cana-deaçúcar tratada tenha prejudicado a fermentação ruminal, provocando alterações no consumo e no balanço de nitrogênio. Menores valores de nitrogênio retido também foram observados por Moraes et al. (2008) ao utilizarem cana-de-açúcar tratada com $1 \%$ de óxido de cálcio na dieta de novilhas, os quais registraram valores de 52,2 e 42,5 g/dia, respectivamente, nas dietas com cana-de-açúcar in natura e tratada com 1\% de óxido de cálcio. Neste estudo, houve redução do consumo nos animais alimentados com dietas com óxido de cálcio.

Segundo Van Soest (1994), aumentos na ingestão de nitrogênio estão associados à maior produção de ureia no fígado e à maior excreção de ureia via urina, enquanto a baixa ingestão conduz a redução na excreção de ureia na urina para manutenção do pool de ureia plasmático, que está sob controle fisiológico homeostático. A menor ingestão de nitrogênio observada neste estudo refletiu no balanço de nitrogênio, mas as excreções de nitrogênio nas fezes e urina mantiveram-se constantes. O mesmo foi observado para a excreção de ureia na urina (Tabela 4), a qual não foi influenciada $(\mathrm{P}>0,05)$ pela alteração na ingestão de nitrogênio provocada pelo tratamento da cana-de-açúcar com óxido de cálcio.

As concentrações de $\mathrm{N}$ ureico na urina e no plasma e as excreções diárias de ureia e $\mathrm{N}$ ureico na urina não foram influenciadas $(\mathrm{P}>0,05)$ pelo tratamento da cana-de-açúcar com óxido de cálcio (Tabela 4). Acredita-se que o uso de 1\% de ureia na cana-de-açúcar no momento de fornecimento das dietas contribuiu para a ausência de efeito nas concentrações e excreções de ureia e $\mathrm{N}$ ureico na urina ou no plasma.

De acordo com Broderick \& Clayton (1997), a concentração elevada de ureia plasmática está relacionada à utilização ineficiente da PB da dieta. Embora o teor de $\mathrm{N}$ retido tenha reduzido, devido ao menor consumo de nitrogênio, as concentrações de $\mathrm{N}$ ureico no plasma observados neste estudo mantiveram-se constantes, logo a similaridade entre esses valores está relacionada à presença da ureia em proporções semelhantes nas dietas.

De acordo com Harmeyer \& Martens (1980), a quantidade de ureia sintetizada no fígado é proporcional à concentração 
de amônia produzida no rúmen e sua concentração sanguínea está diretamente relacionada ao aporte proteico e à relação energia:proteína dietética. De forma geral, as concentrações de $\mathrm{N}$-ureico no plasma observadas neste trabalho estão de acordo com os descritos por Moraes et al. (2008), que, em pesquisa com novilhas alimentadas com cana-de-açúcar tratada ou não com $1 \%$ de óxido de cálcio, relataram valores de 20,5 e 28,3, respectivamente. As concentrações de N-ureico plasmático obtidas neste estudo também se aproximam das observadas por Magalhães et al. (2005), que avaliaram doses de ureia de $0 ; 0,65 ; 1,30$; e 1,95\% na dieta de novilhos leiteiros e verificaram valores entre 12,8 e $18,5 \mathrm{mg} / \mathrm{dL}$.

$\mathrm{O}$ teor de $\mathrm{N}$-ureico no plasma tem sido utilizado para obtenção de informações adicionais sobre nutrição proteica de ruminantes, por meio da resposta metabólica à determinada dieta. Desse modo, é possível evitar perdas econômicas advindas do fornecimento excessivo de proteína dietética e de possíveis prejuízos produtivos, reprodutivos e ambientais. Neste trabalho os valores de N-ureico no plasma não foram afetados pelo tratamento da cana com óxido de cálcio e situaram-se numa faixa entre 14,7 e 16,5 mg/dL. Valadares et al. (1997) afirmaram que as concentrações de nitrogênio no plasma e na urina estão correlacionadas e que valores de 14,0 a $16 \mathrm{mg} / \mathrm{dL}$ de $\mathrm{N}$-ureico plasmático representariam limites a partir dos quais estariam ocorrendo perdas de proteína dietética.

As excreções de alantoína, ácido úrico e purinas totais e as purinas microbianas absorvidas não foram influenciadas $(\mathrm{P}>0,05)$ pelas doses de óxido de cálcio utilizadas no tratamento da cana-de-açúcar (Tabela 5). Do mesmo modo, a produção de nitrogênio e PB microbiana (g/dia) e a eficiência microbiana, g PB/kg de NDT, também não foram afetadas $(\mathrm{P}>0,05)$ pelo uso do óxido de cálcio no tratamento da cana-de-açúcar.

Os valores médios obtidos para as excreções de alantoína e ácido úrico neste estudo, respectivamente, de 111,5 e $8,6 \mathrm{mmol} /$ dia, estão de acordo com os observados por Chizzotti et al. (2006), de 111,6 e 10,8 em novilhas com peso vivo de $235 \mathrm{~kg}$. Também são semelhantes aos observados pelos autores os valores para as purinas totais (122,4, mmol/dia) e absorvidas (126,0, mmol/dia) e para a síntese de proteína microbiana (499,4 gPBmic/dia) (Tabela 5). Os autores observaram que a eficiência de síntese microbiana não diferiu entre as dietas, mas variaram entre as faixas de peso.

A proporção de alantoína nas purinas totais não diferiu entre as dietas e apresentou média de 92,8\%, próxima aos valores obtidos por Rennó et al (2008), de 91,70 e 93,36\%, em dois experimentos e por Chizzotti et al. (2006), de $90,7 \%$. Valores inferiores, de 87,90; 87,17 e 85\%, foram encontrados por Leão et al. (2004, 2005), Rennó et al. (2000) e Verbic et al. (1990), respectivamente.

As disponibilidades ruminais de energia e nitrogênio são os fatores nutricionais que mais afetam o crescimento microbiano (Clark et al., 1992), portanto, a relação volumoso:concentrado na dieta poderia influenciar o crescimento microbiano, assim, a semelhança entre a relação volumoso:concentrado de 71:29 nas dietas experimentais pode ter refletido na ausência de efeito significativo na produção e eficiência microbiana. Taxas mais rápidas de

Tabela 5 - Excreções de derivados de purinas, síntese de nitrogênio e proteína microbiana e eficiência microbiana em novilhas alimentadas com dietas contendo cana-de-açúcar tratada com óxido de cálcio

\begin{tabular}{|c|c|c|c|c|c|c|c|c|}
\hline \multirow[t]{3}{*}{ Item } & \multirow{3}{*}{$\begin{array}{l}\text { Cana in } \\
\text { natura }\end{array}$} & \multirow{2}{*}{\multicolumn{3}{|c|}{$\begin{array}{l}\text { Óxido de cálcio na } \\
\text { cana-de-açúcar (\% MN) }\end{array}$}} & \multirow[t]{3}{*}{ CV (\%) } & \multicolumn{3}{|c|}{ Efeito $^{1}$} \\
\hline & & & & & & \multirow{2}{*}{$\begin{array}{l}\text { Controle vs. } \\
\text { óxido de cálcio }\end{array}$} & \multirow[t]{2}{*}{ Linear } & \multirow[t]{2}{*}{ Quadrático } \\
\hline & & 0,75 & 1,5 & 2,25 & & & & \\
\hline \multicolumn{9}{|c|}{ Excreções urinárias (mmol/dia) } \\
\hline Alantoína & 116,1 & 114,3 & 109,4 & 106,0 & 15,9 & ns & ns & ns \\
\hline Ácido úrico & 9,3 & 8,1 & 8,5 & 8,3 & 28,5 & ns & ns & ns \\
\hline Purinas totais & 125,5 & 122,4 & 117,9 & 114,3 & 14,9 & ns & ns & ns \\
\hline \multicolumn{9}{|c|}{ Purinas microbianas (mmol/dia) } \\
\hline Absorvidas & 121,6 & 118,3 & 113,2 & 108,9 & 17,2 & ns & ns & ns \\
\hline \multicolumn{9}{|c|}{ Em \% das purinas totais } \\
\hline Alantoína & 92,7 & 93,2 & 92,7 & 92,6 & 2,2 & ns & ns & ns \\
\hline Ácido úrico & 7,3 & 6,8 & 7,3 & 7,4 & 28,0 & ns & ns & ns \\
\hline \multicolumn{9}{|c|}{ Síntese de nitrogênio e PB microbiana (g/dia) } \\
\hline N-microbiano & 88,4 & 86,0 & 82,3 & 79,2 & 17,2 & ns & ns & ns \\
\hline PB-microbiana & 552,6 & 537,5 & 514,5 & 594,8 & 17,2 & ns & ns & ns \\
\hline \multicolumn{9}{|c|}{ Eficiência microbiana } \\
\hline g PB/kg NDT & 179,0 & 183,2 & 191,0 & 194,1 & 20,3 & ns & ns & ns \\
\hline
\end{tabular}


crescimento microbiano atribuídas à maior disponibilidade de nutrientes, associadas à passagem mais rápida de microrganismos para o abomaso, podem reduzir os requisitos de mantença da microbiota ruminal (Clark et al., 1992) e aumentar a eficiência microbiana.

O valor médio encontrado para eficiência de síntese microbiana foi de 186,8 g PB mic/kg NDT e situou-se em patamares superiores àquele referenciado pelo NRC (2001), de 130 g PB mic/kg NDT, e por Valadares Filho et al. (2006), de 120 g PB mic/kg NDT. A síntese de proteína microbiana depende, em grande parte, da disponibilidade de carboidratos e nitrogênio no rúmen (Clark et al., 1992; NRC, 2001), de modo que o crescimento microbiano é maximizado pela sincronização entre a disponibilidade da energia fermentável e o nitrogênio degradável no rúmen (Russell et al., 1992). Estima-se que não houve limitação para o crescimento dos microrganismos, contudo, o teor fibroso da cana-de-açúcar pode ter limitado a ingestão de NDT, que acarretou maior eficiência microbiana.

\section{Conclusões}

O tratamento da cana-de-açúcar reduz o balanço de compostos nitrogenados, mas não altera as concentrações de nitrogênio ureico na urina e no plasma nem as excreções de nitrogênio ureico e ureia na urina. Não há vantagens em utilizar óxido de cálcio no tratamento da cana-de-açúcar, pois o fornecimento de cana-de-açúcar tratada não altera a produção de compostos nitrogenados microbianos nem a eficiência de síntese microbiana em novilhos.

\section{Referências}

BARBOSA, A.M.; VALADARES, R.F.D.; VALADARES FILHO, S.C. et al. Efeito do período de coleta de urina, dos níveis de concentrado e de fontes protéicas sobre a excreção de creatinina, de uréia e de derivados de purina e a produção microbiana em bovinos Nelore. Revista Brasileira de Zootecnia, v.35, n.3, p.870-877, 2006.

BALIEIRO NETO, G.; SIQUEIRA, G.R.; REIS, R.A. et al. Óxido de cálcio como aditivo na ensilagem de cana-de-açúcar. Revista Brasileira de Zootecnia, v.36, n.5, p.1231-1239, 2007.

BRODERICK, G.A.; CLAYTON, M.K. A statistical evaluation of animal and nutritional factors influencing concentrations of milk urea nitrogen. Journal of Dairy Science, v.80, n.11, p.2964-2971, 1997.

CASALI, A.O.; DETMANN, E.; VALADARES FILHO, S.C. et al. Influência do tempo de incubação e do tamanho de partículas sobre os teores de compostos indigestíveis em alimentos e fezes bovinas obtidos por procedimentos in situ. Revista Brasileira de Zootecnia, v.37, n.2, p.335-342, 2008.

CASALI, A.O.; DETMANN, E.; VALADARES FILHO, S.C. et al. Estimação de teores de componentes fibrosos em alimentos para ruminantes em sacos de diferentes tecidos. Revista Brasileira de Zootecnia, v.38, n.1, p.130-138, 2009.
CHEN, X.B.; GOMES, M.J. Estimation of microbial protein supply to sheep and cattle based on urinary excretion of purine derivatives - an overview of technical details. Bucksburnd: Rowett Research Institute/International Feed Research Unit, 1992. 21p. (Occasional publication).

CHIZZOTTI, M.L.; VALADARES FILHO, S.C.; VALADARES, R.F.D. et al. Excreção de creatinina em novilhos e novilhas. In: REUNIÃO ANUAL DA SOCIEDADE BRASILEIRA DE ZOoteCniA, 41., 2004, Campo Grande. Anais... Campo Grande: Sociedade Brasileira de Zootecnia, 2004. (CD-ROM).

CHIZZOTTI, M.L.; VALADARES FILHO, S.C.; VALADARES, R.F.D. et al. Consumo, digestibilidade e excreção de ureia e derivados de purinas em novilhas de diferentes pesos. Revista Brasileira de Zootecnia, v.35, n.4 p.1813-1821, 2006.

CLARK, J.H.; KLUSMEYER, T.H.; CAMERON, M.R. Microbial protein synthesis and flows of nitrogen fractions to the duodenum of dairy cows. Journal of Dairy Science, v.75, n.8, p.2304-2323, 1992.

DETMANN, E.; PAULINO, M.F.; ZERVOUDAKIS, J.T. et al. Cromo e indicadores internos na determinação do consumo de novilhos mestiços, suplementados, a pasto. Revista Brasileira de Zootecnia, v.30, n.5, p.1600-1609, 2001.

DETMANN, E.; SOUZA, A.L.; GARCIA, R. et al. Avaliação do "vício de tempo" de indicadores internos em ensaio de digestão com ruminantes. Arquivo Brasileiro de Medicina Veterinária e Zootecnia, v.59, n.1, p.182-188, 2007.

FERNANDES, A.M.; QUEIROZ, A.C.; LANA, R.P. et al. Estimativas da produção de leite por vacas holandesas mestiças, segundo o sistema CNCPS, em dietas contendo cana-de-açúcar com diferentes valores nutritivos. Revista Brasileira de Zootecnia, v.30, n.4, p.1350-1357, 2001.

HALL, M.B. Challenges with nonfiber carbohydrate methods. Journal of Animal Science, v.81, n.12, p.3226-3232, 2003.

HARMEYER, J.; MARTENS, H. Aspects of urea metabolism with reference to the goat. Journal of Dairy Science, v.63, n.10, p.1707-1728, 1980.

ÍTAVO, L.C.V.; VALADARES FILHO, S.C.; SILVA, F.F. et al. Comparação de indicadores e metodologia de coleta para estimativas de produção fecal e fluxo de digesta em bovinos. Revista Brasileira de Zootecnia, v.31, n.4, p.1833-1839, 2002.

LEÃO, M.I.; VALADARES FILHO, S.C.; RENNÓ, L.N. et al. Consumos e digestibilidades aparentes totais e parciais de matéria seca, matéria orgânica, proteína bruta e extrato etéreo em novilhos submetidos a três níveis de ingestão e duas metodologias de coleta de digestas abomasal e omasal. Revista Brasileira de Zootecnia, v.33, n.6, p.1604-1615, 2004.

LEÃO, M.I.; VALADARES FILHO, S.C.; RENNÓ, L.N. et al. Consumos e digestibilidades aparentes totais e parciais de carboidratos totais, fibra em detergente neutro e carboidratos não fibrosos em novilhos submetidos a três níveis de ingestão e duas metodologias de coleta de digestas abomasal e omasal. Revista Brasileira de Zootecnia, v.34, n.2, p.670-678, 2005.

LICITRA, G.; HERNANDEZ, T.M.; VAN SOEST, P.J. Standardization of procedures for nitrogen fracionation of ruminant feed. Animal Feed Science Technological, v.57, n4, p.347-358, 1996.

MAGALHÃES, A.L.R.; CAMPOS, J.M.S.; VALADARES FILHO, S.C. et al. Cana-de-açúcar em substituição à silagem de milho em dietas para vacas em lactação: desempenho e viabilidade econômica. Revista Brasileira de Zootecnia, v.33, n.5, p.1292-1302, 2004.

MAGALHÃES, K.A.; VALADARES FILHO, S.C.; VALADARES, R.F.D. et al. Produção de proteína microbiana, concentração plasmática de ureia e excreções de ureia em novilhos alimentados com diferentes níveis de ureia ou casca de algodão. Revista Brasileira de Zootecnia, v.34, n.4 p.1400-1407, 2005.

MERTENS, D.R. Gravimetric determination of amylase-treated neutral detergent fiber in feeds with refluxing in beakers or crucibles: collaborative study. Journal of AOAC International, v.85, p.1217-1240, 2002. 
MORAES, K.A.K.; VALADARES FILHO, S.C.; MORAES, H.B.K. et al. Cana-de-açúcar tratada com óxido de cálcio fornecida com diferentes níveis de concentrado para novilhas de corte em confinamento. Revista Brasileira de Zootecnia, v.37, n.7, p.1293-1300, 2008.

NATIONAL RESEARCH COUNCIL - NRC. Nutrient requirements of dairy cattle. 7.ed. Washington: National Academy Press, 2001. 450p.

OLIVEIRA, M.D.S.; ANDRADE, A.T.; BARBOSA, J.C. et al. Digestibilidade da cana-de-açúcar hidrolisada, in natura e ensilada para bovinos. Ciência Animal Brasileira, v.8, n.1, p.41-50, 2007.

PAULINO, M.F.; DETMANN, E.; VALADARES FILHO. S.C. Suplementação animal em pasto: energética ou proteica? In: SIMPÓSIO SOBRE MANEJO ESTRATÉGICO DA PASTAGEM, 3., 2006, Viçosa, MG. Anais... Viçosa, MG: SIMFOR, 2006. p.359-392.

RENNÓ, L.N.; VALADARES FILHO, S.C.; VALADARES, R.F.D. et al. Níveis de ureia na ração de novilhos de quatro grupos genéticos: estimativa da produção de proteína microbiana por meio dos derivados de purinas na urina utilizando duas metodologias de coleta. Revista Brasileira de Zootecnia, v.37, n.3 p.546-555, 2008.

RENNÓ, L.N.; VALADARES, R.F.D.; LEÃO, M.I. et al. Estimativa da produção de proteína microbiana pelos derivados de purinas na urina em novilhos. Revista Brasileira de Zootecnia, v.29, n.4, p.1223-1234, 2000.

RIBEIRO, L.S.O.; PIRES, A.J.V.; CARVALHO, G.G.P. et al. Composição química e perdas fermentativas de silagem de canade-açúcar tratada com ureia ou hidróxido de sódio. Revista Brasileira de Zootecnia, v.39, n.9, p.1911-1918, 2010.

RUSSELL, J.B.; O'CONNOR, J.D.; FOX, D.J. et al. A net carbohydrate and protein system for evaluating cattle diets: I. Ruminal fermentation. Journal of Animal Science, v.70, n.11, p.3551-3561, 1992.
SILVA, D.J., QUEIROZ, A.C. Análise de alimentos: métodos químicos e biológicos. Viçosa, MG: UFV, 2002. 235p.

SNIFFEN, C.J.; O’CONNOR, D.J.; Van SOEST, P.J. et al. A net carbohydrate and protein system for evaluating cattle diets: carbohydrate and protein availability. Journal of Animal Science, v.70, n.12, p.3562-3577, 1992.

STATISTICAL ANALYSES SYSTEM - SAS. SAS user's guide. Cary: 1999. v.8, 295p.

VALADARES, R.F.D.; GONÇALVES, L.C.; SAMPAIO, I.B.M. et al. Níveis de proteínas em deitas de bovinos. 3. pH, amônia e eficiência microbiana. Revista Brasileira de Zootecnia, v.26, n.6, p.1264-1269, 1997.

VALADARES, R.F.D.; BRODERICK, G.A.; VALADARES FILHO, S.C. et al. Effect of replacing alfalfa with high moisture corn on ruminal protein synthesis estimated from excretion of total purine derivatives. Journal of Dairy Science, v.82, n.12, p.2686-2696, 1999.

VALADARES FILHO, S.C.; PINA, D.S.; CHIZZOTTI, M.L. et al. Degradação ruminal da proteína dos alimentos e síntese de proteína microbiana. In: VALADARES FILHO, S.C.; PAULINO, P.V.R.; MAGALHÃES, K.A. (Eds.) Exigências nutricionais de zebuínos e tabelas de composição de alimentos. Viçosa, MG: DZO-UFV, 2006. p.13-44.

VAN SOEST, P.J. Nutritional ecology of the ruminant. 2.ed. Ithaca: Cornell University Press, 1994. 476p.

VERBIC, J.; CHEN, X.B.; MACLEOD, N.A. et al. Excretion of purine derivatives by ruminants. Effect of microbial nucleic acid infusion on purine derivative excretion by steers. Journal of Agricultural Science, v.114, n.3, p.243-248, 1990.

WEISS, W.P. Energy prediction equations for ruminant feeds. In: CORNELL NUTRITION CONFERENCE FOR FEED MANUFACTURERS, 61., 1999, Ithaca. Proceedings... Ithaca: Cornell University, 1999. p.176-185. 